\title{
Multimedia Aided Language Teaching: An Ideal Pedagogy in the English Language Teaching of Bangladesh
}

\author{
Md. Kawser Ahmed ${ }^{1}$
}

${ }^{1}$ Assistant Professor, Department of English, Z. H. Sikder University of Science \& Technology, Bangladesh

Correspondence: Department of English,Z. H. Sikder University of Science \& Technology, Madhupur, Kartikpur, Bhedergonj, Shariatpur, Bangladesh, Email: kawser.zhsust@ gmail.com, Tel: +8801751539582

To cite this article: Ahmed, M. K. (2018). Multimedia Aided Language Teaching: An Ideal Pedagogy in the English Language Teaching of Bangladesh. American International Journal of Social Science Research, 3(1), 39-47. Retrieved from https://www.cribfb.com/journal/index.php/aijssr/article/view/220

Received: December 2, $2018 \quad$ Accepted: December 10, $2018 \quad$ Online Published: December 20, 2018

\begin{abstract}
Teaching English language around the globe is not only concentrated on grammars, series of writings and face to face interviews through conventional style but also centralized on the modern equipment, information and technology. Day to day updated accessories have made a tremendous progress in the pedagogy of English and ensured maximum benefits and acceptability among teachers and learners simultaneously. Observing the global usability and frequency, English language has appeared as a technology-but not as a language only but also as a channel of communication and language teaching. Application of multimedia in teaching-learning of English has earned best appreciation at any level of education and students have found English as an easy means of communication, conversation and interact with teachers with the blessing of multimedia and updated materials of language teaching. On the contrary, it is pitiful to observe that unavailability of modern accessories and elements in teaching English shows the namesake picture of multimedia used in third world countries especially in Bangladesh. This paper will focus on the significant progresses in the application of multimedia; take up of class with the aid of modern equipment and practical scenario of the use of multimedia in schools, colleges and universities of Bangladesh where multimedia based classroom is getting popular between teachers and students equally.
\end{abstract}

Keywords: Accessories, Multimedia, Pedagogy, Technology, Scenario

\section{Introduction}

Multimedia based teaching-learning at any layer of education like primary education, secondary education and tertiary education is a very frequent and familiar concept. Especially the application of multimedia aided classroom can be found in university education, private schools at city environment and English medium schools of Bangladesh. With the progress of modern technology, educational institutes are getting oriented to technology based teaching-learning system. "Multimedia is the exciting combination of computer hardware and software that allows you to integrate video, animation, audio, graphics, and test resources to develop effective presentations on an affordable desktop computer" (Susikaran, 2015). The term 'Multimedia' refers to compute or laptop, overhead projector (OHP), speaker and other related tools and cables which are considered precondition to operate these electronic devices in a real life classroom. "Several trends seem to be emerging. Computers are becoming increasingly available in schools around the globe. Governments, teachers and parents are advocating the networking of these computers, and making long-range plans for their use all levels of education. New demands are then being made on teachers to use the technology creatively, leading to a steep rise in the membership of relevant mailing lists and the number of available Internet training courses for teachers" (Teeler and Gray, 2000). Technology is a strong determiner in the way of implementing multimedia and its tools in a language classroom. The concept of multimedia is not impractical and far cry topic in the education system of Bangladesh. Rather it has a positive impact in the modernization of education, digitization 
of learning system and facilitation of teaching methodology. "Application of information and communication technology (ICTs) is an open field, carrying inherent traits similar to any other innovation in serving the needs of citizenry. The initiatives by UNDP and USAID supported Access to Information (a2i) programme aims to make teaching and learning more effective and enjoyable for both students and teachers using ICTs" (Access to Information (a2i), Prime Minister's Office of Bangladesh, 2014). Access to Information (a2i) has made a tremendous revolution in the materialization of Information and Communication Technology for the greater interest of teachers and students who have been accustomed to adapting to the use of technology and its tools for the purpose of education. "Establishment of smart classrooms (multimedia classroom or MMC), which started with 7 schools and 23 teachers in 2010, sought to reform the teacher-centric system into more oriented towards motivating students to engage in classrooms. In the second phase, a private sector company came forward to establish these classrooms in a few hundred secondary schools. The most remarkable transformation was empowerment of teachers who were trained to create multimedia content independently, rather than depending on curriculum and multimedia experts" (Access to Information (a2i), Prime Minister's Office of Bangladesh, 2014). Now we need to make the realization of reality, conceptualization of the actual context of Bangladesh and presentation of authentic picture of the application of multimedia in the arena of teaching-learning in Bangladesh. Bangladesh is one the low-mid income bracketed countries of the world where meeting up of basic needs for the mass people is still the major challenge. A large of number of people stay below the poverty line, get deprived of modern medical facilities and remain unemployed after the completion of graduation. The growing population within the small scaled land is experiencing the political instability, social vices and religious conflicts. This paper will concentrate on application of multimedia in language teaching of Bangladesh, practicable impediments in the way of materialization of technology oriented classroom and informational analysis to have an overall glimpse of teaching-learning in Bangladesh.

2. Multimedia Oriented Language Teaching: An Overview in the Context of Bangladesh

The present age is marked with massive development of Information and Communication Technology (ICT) and teaching of language to the learners in English as Second Language (ESL) context is a vibrant and most rated topic. The initiation of multimedia to the language teaching in Bangladesh is not very far distant. Bangladesh is still in the beginning level to implement the concept of multimedia wholeheartedly and it is going through a series of upheavals in the fullest application of this newly fixed concept. Teachers and students are very used to adapting with equipment of multimedia and they do not find multimedia as a good way of teaching English as a second language. Like other languages, English comprises of four skills such as reading, writing, listening and speaking. In every single skill, there is a great scope for teachers and students to use electronic devices like computer, overhead projector (OHP) and speaker in classroom. Students will have real life learning from visual presentation of topic, they will be able to listen to what video materials are played on and read out in chorus reading passages or reading articles presented by course teacher.

Technology can have a great role in the way English is taught and in the way a student learns. It can nurture interaction and motivation among students in various ways that a class taught without technology could not do it simply (Boles, 2011). Since Bangladesh has to maintain criteria and conditions of global language teaching patterns and methods, it attempts certain measures to make classroom decorated with modern amenities like internet access inside and outside of campus of university, Wi-Fi facility for students working in language lab, preparing power point presentation through computer and word processing for submitting assignment. Teachers and students are getting adjusted into web based education especially at university education where four skills are taught as mandatory for the incumbent graduates.

Evans (2009) found that forty-eight percent school kids who were between age group eleven and fourteen expressed that computer motivated them to do their schoolwork. This picture is significantly seen among the young learners who are very accustomed to using computer and they try out to complete their homework through computer.

Information and Communication Technology (ICTs) creates a great enthusiasm among learners not only they play games, listen to songs and watch movies, but also they are able to draw pictures, insert table for school works and write in word page for academic purposes. Students can hear conversation by which they will be able to get the manner of pronunciation, teacher can show students a demonstration of pair discussion or dialog and students might be motivated for simulation where they will make it live discussion before other students. In fact most of the universities especially private universities of Bangladesh are greatly using ICTs for English language teaching and they arrange audio and video materials for students. Almost every private university of Bangladesh has separate English language institute, lab or center for students can have more familiarization with English language and they can learn English with the aid of speaker, high definition video clip and projection on screen. The historical background of language gets broken down and teachers inspire students to prepare, practice and produce their presentation through projector.

Passey et al. (2004) investigate that Information and Communication Technology positively makes an impact on the motivation of learning for both boys and girls. The study also showed that boys have made the study habit 
from 'burst' to a more productive and time invested, 'persistent' approach. It is softly understood that the success rate of ICTs within the classroom depends greatly on how they are applied within the curriculum.

Language teaching and technology of Bangladesh are in a simultaneous position. Language teachers focus on the presentation of topic like linguistics and its various elements through power point presentation because it ensures credibility and acceptability among learners. Teachers discuss the topic initially to students and they are invited to watch what has been discussed before students. Since learners have the blend of conceptual knowledge and video performance based upon certain topic, their learning becomes authentic and solid because they find a good match between what thought is discussed in theory and how they need to be done in practice. It can be said that most of the Bangladeshi language classrooms are modernized with multimedia accessories where students can have more participatory learning and they can have a wide scope of demonstrating power.

In addition, Government of Bangladesh has political manifesto that by 2021 in every sector including education will be digitized. Teaching especially pedagogy of teaching-learning will be made with curriculum of latest syllabus and multimedia oriented. How to learn a foreign language, literature, culture, history and society is a major concern of educationists especially language experts. They organize seminars, workshops and conferences thinking about the pedagogical strategies and outlining pragmatic steps in which English can be taught in an effective manner.

The education system of Bangladesh is branched into different segments where we find mainstream education like Bengali medium, English medium and Madrasah education (based in religious concepts) and sub stream education system like vocational and technical education. Considering the total participation of students involved in education, majority belong to the mainstream education and a small scale of students is getting involved in sub stream education.

Private schools, colleges and universities are getting fast in comparison with public schools, colleges and universities regarding the application of multimedia in classroom because private educational institutes have self-finance where public educational institutes are subject to getting funds meeting up bureaucratic complexity. Language teachers of private institutes have a great scope to conduct class with the aid of multimedia, demonstration of theoretical topic and relevancy of video materials which make teaching-learning easy for students. The scenario of language classroom of Bangladesh is that teacher comes inside class with laptop and projector and teacher makes a power point presentation wherever it requires. In place of conventional method of teaching-learning, students are more inclined to receive knowledge on four skills with audio-visual system for it ensures compact style of teaching. In a word, it is meant that English language teaching has earned its effectiveness with the aid of multimedia.

3. Review of Literature

Researches and articles are abundantly found on the application of multimedia in the ELT classroom. Many linguists, ELT practitioners and professionals have talked much on multimedia and they have chalked out for what reasons teachers should take up classes with the aid of multimedia. A number of literatures related to this topic have been reviewed in this article:

Kern and Warschauer (2000:13) point out that:

"if our is to help students enter into new authentic discourse communities, and if those discourse communities are increasingly located online, then it seems appropriate to incorporate online activities for their social utility as well as for their perceived particular pedagogical value".

The statement emphasizes on authentic teaching materials which can be taught via technology and this sort of educational technology complements social needs and teaching and learning activities.

Meskil (2005:33) outlines two aspects of technology highlighting two implications:

"Like other human tools, computers can be used to assemble, construct, attach, detach disassemble, connect and fashion products. Like other tools their use influences the ways we think, behave and communicate".

Computers are largely used in language classroom for many different purposes that are used for real life classroom and they can make a good influence in the same way what human brains perceive and interact with others.

"The multimedia language labs and multimedia-based network system provide authentic and native English listening and speaking environment and enable students to have more opportunities of practicing their listening and speaking in class and out of class. The multimedia teaching software, which is well designed and featured as the various types of authentic English materials, is now commonly used as the major teaching tool during the process of listening and speaking teaching in China. The teachers act as the designer, organizer and coordinator for students' listening and speaking activities in class and out of class. The students are no longer the "taperecorder". Instead, they become active listeners and interpreters who are supposed to conduct a series of listening and speaking activities" (Xian Tang, 2011).

The statement sums up that multimedia ensures authenticity in English language teaching and learning and creates a native like environment where students feel comfortable in mutual interaction and listening to audio track. In multimedia based education, teachers facilitate students in utilizing technological aides like educational software for ELT purposes. 
Technology education includes four distinct but interrelated strands: technological literacy, technological awareness, technological capability, and information technology (ASE, 1988).

- Technological literacy is defined as familiarity with the content and methodologies of a range of technologies.

- Technological awareness means awareness of the personal, moral, social, ethical, economic and environmental implications of technological developments.

- Technological capability means the ability to tackle a technological problem, both independently and in co-operation with others.

- Information technology means competence and confidence in the technological handling of information (Layton, 1993).

4. Multimedia Aided Language Teaching in Bangladesh: Visible Limitations

It is beyond doubt that Information and Communication Technology (ICT) and multimedia have brought about radical developments in the English language teaching of Bangladesh. Teachers can show conjugation of verb and subject verb agreement through colorful slides, play audio file or video clip to make learners understand about exact pronunciation and show written documents or compositions like paragraph, essay and report writing with a detailed step out. Despite having all of the blessings of multimedia based teaching-learning, Bangladesh is suffering from a series of visible limitations in the proper implementation in this regard. Following are a set of mostly found limitations in the way of implementing multimedia oriented class in English language teaching:

4.1 Deficit of Budget and Limitation of Resources

Since multimedia requires a set of devices like computer, laptop, overhead projector, interactive white board (IWB) and other essential tools, educational institutes cannot manage these products because of shortage of budget and other financial crises. The percentage of budget allocated for modern language classroom remains beyond reach. It is known to all that most of the educational institutes especially schools and colleges are set up in rural and suburb environment. Students studying in these institutes come from poor family and thus they cannot maintain tuition fees and educational expenses which obstruct the flow of money to particular schools. As a result, authority of those schools cannot manage fund to purchase expensive multimedia devices for English language teaching. For conducting a standard language, school authority needs to manage fifty computers for conducting language class and training them up with basic skills. "Critics of IWBs worry about the amount of money they cost. There is some concern, too, about the fact that currently most IWBs are at the front of the classroom and thus tend to promote teacher (and learner)-fronted behaviours, and are less favourable for groupwork" (Harmer, 2001). It can be understood what Harmer (2001) would like to talk about the price concern regarding these costly accessories.

4.2 Shabbiness in Infra-structural Establishments:

In the context of Bangladesh, multimedia is still a fantasy scheme because a large number of educational institutes have poor infra-structural set ups. Since these institutes are established in rural environment and marginal point of country, modern English language teaching methodology is an impossible concept. Educational institutes do not have socket point, plug in point, white board, projector screen and sufficient length of cables. Teachers are unable to keep laptops and projectors in suitable locations. In addition, there is a good scope of being stolen of these expensive accessories which result in a classroom without having multimedia classroom.

4.3 Power Crisis and Lack of Constant Electricity Supply:

Power crisis is one of the acute problems in the teaching of English language among Bangladeshi learners through multimedia. If we make a statistical analysis that fifty percent of total population is within the reach of power facility (Economic Studies of Bangladesh, 2017-1018). Educational institutes having electric connection heavily suffer from frequent load shedding and low voltage which in turn brings about nothing to be displayed or monitored on projector screen. Learners sitting in language classroom and lab feel bored when there is a disruption in smooth power operation and they feel 'loss of interest' in learning language. In the village environment, the Rural Electrification Board of Bangladesh (REB) cannot suffice huge needs of power for operating multimedia.

\subsection{Poor Network and Slow Internet Speed:}

Internet is perhaps the easiest and most reliable source to collect information, aggregate concepts on different areas of language and assimilate for better presentation among learners. In fact internet unbounds huge scopes for facilitating teaching-learning in language classroom. One of the advantages of using computers and the Internet is that students can access the material and practice a lesson repeatedly, which allows for learning from mistakes through continual, non-judgmental feedback. In addition, the Internet and school-safe social networking websites enable students of different cultures and languages to connect (Butler-Pascoe and Hufstedler, 2010).

All of the step by step procedures are accomplished in power point presentation sheet and teachers work to draw students' attention to study through preparing slides and showing animated clip. The Internet is a key tool for accommodating all of the variations that confront the English language teacher. 
Engaging students with multi-media websites that stir the imagination enables the teacher to present information in unique ways, shapes and forms, as well as in different languages (Butler-Pascoe and Hufstedler, 2010). It is pitiful to see that Bangladesh is suffering from poor networking of internet and subsequently slow speed of internet results in sloth in education especially gathering information regarding listening and speaking inside classroom. From a recent study done by the Dhaka Tribune one of the English dailies of Bangladesh, Bangladesh is ranked $120^{\text {th }}$ among 122 countries in terms of mobile internet speed on global mobile and fixed broadband internet speed. The broadband speed of Bangladesh has shown a comparatively better performance; the country stands at 78 among 133 countries. Furthermore, the average download speed offered by mobile internet services in Bangladesh is $5.17 \mathrm{Mbps}$, while it is $15.91 \mathrm{Mbps}$ in broadband connections. The picture of internet speed and performance is not in a steady state and for this reason language teachers cannot organize their lesson plan and course manual in an effective way because most of the books and materials of language teaching are expensive and beyond purchase capability.

4.5 Unavailability of Well-trained Up Teachers for Smooth Operation:

Bangladesh is one of the fewest countries where ELT teachers can engage themselves in teaching position without having prior adequate training, classroom experience and follow up of effective policy regarding teaching language. Basing upon only university education and theoretical knowledge, ELT teachers get into the realm of teaching language which gradually brings about nothing positive in effective classroom. Since these teachers do not have pre-service experience in language teaching, they do not know how to take class with full access of multimedia. A great number of fresh graduates feel nerving and diseasing when they find multimedia accessories like laptop, overhead projector (OHP) and speaker by which teachers are subject to conduct to class incessantly. Inability to operate multimedia causes failure in language teaching-learning in English language in Bangladesh. It can easily be understood that application of multimedia and English language teaching are closely tied to each other.

Jonasses (2000) defined multimedia as the use of different means which include text, movie clips, audio recording and graphics to communicate through the aid of computer systems. The focus of assimilating multimedia into the teaching-learning process refers to the dates back to the $1950 \mathrm{~s}$ when few classrooms were equipped with phonograms and broadcasts recordings (Mudge, 1999). In the context of language teaching, the use of multimedia has become one of the basic skills that an individual must possess today for effective operation of class. In fact, multimedia has changed the nature of education and language learning in all of the aspects (Rubin, 1987).

From the discussion mentioned above, we can come to a good term that an ELT teacher needs to have a strong knowledge in fair conducting of multimedia. Teaching-learning except having multimedia will show us fragility of language teaching and incompleteness in a wide variety linguistic elements like phonetics, sound patterns and sound features, intonation, stress marking and rhythm in speech.

The application of multimedia in an EFL setting has turned the classroom into a more "dynamic" and interactive place in an article published by Amine, Benachaiba, and Guemide (2012). They in fact concentrated on investigating the consensus of the positive impact of multimedia on language pedagogy. The paper also suggested the use of multimedia for the extraordinary benefits they carry into the classroom. It outlined that multimedia nurtures students' interests in a given field.

\section{Methodology}

I have conducted a qualitative research to get an authentic picture whether multimedia based English language teaching will be effective and relevant in the perspective of Bangladesh. My research attempt was a sample in which I tried to find out teachers' impression towards multimedia oriented classroom, what they felt about the application of modern equipment in the realm of language teaching and how they overcame the situation when they faced any obstacle while conducting class through technology in the low mid income country like Bangladesh.

\section{Participants}

To make my qualitative research, I met thirty teachers of which eight teachers were from primary and secondary education, seven teachers from intermediate or college level education and fifteen teachers from university education of Bangladesh. One of the significant aspects of this research was that they taught English as a subject in schools and colleges and taught English as a language in two different public universities of Bangladesh who had specialization on English Language Teaching (ELT). It would be worthwhile to mention that university teachers were more adjusted to taking classes in multimedia environment than school and college teachers because English teaching in university received special attention and teachers were supposed to teach students different aspects of language like pronunciation, distinctive sound features and critical discussion and presentation of literary texts and theories. On the contrary, teachers of English at school and college of Bangladesh taught students how to go through passage or reading comprehension, discussion of grammars and recitation of rhymes or poems through power point projection and electronic devices in a real life classroom. The background of teachers was relevant to mention because it would make us understand how much they coped up with the newly adopted language teaching pattern breaking the conventional methodology of English 
language teaching in Bangladesh. Most of the school teachers were graduate or degree pass holders in different disciplines rather than in English and all of the college and university teachers of Master degree or PhD holders in specific field of education like English language and Literature were from native university and foreign university. Some university teachers had degree or special training in TESL (Teaching English as a Second Language)/TEFL (Teaching English as a Foreign Language) where they were previously accommodated with modern technology like multimedia in classroom.

7. Procedures

As a part of this qualitative research, I presented my interest that I needed their impressions and reactions regarding the application of technology based language teaching in the context of Bangladeshi English language scenario. Initially, I showed a questionnaire furnished with five different questions which reflect how teachers work effectively with the aid of multimedia and where they face possible obstacles as the concept of multimedia based language teaching is not familiar to the language teachers of Bangladesh. They were asked to give their judicious answer in line with setting question reflecting actually how they take classes and how their students are benefitted attending classes in such a multimedia decorated classroom. Acceptance of multimedia based classroom varies because learners of different age groups are involved and they express their divided impressions regarding this newly adopted teaching concept. A set of questions set in questionnaire will be discussed in the section of Result of this paper to have a realistic picture of multimedia based classroom.

8. Results of the Study

8.1 Do language teachers use multimedia in the real life classroom environment?

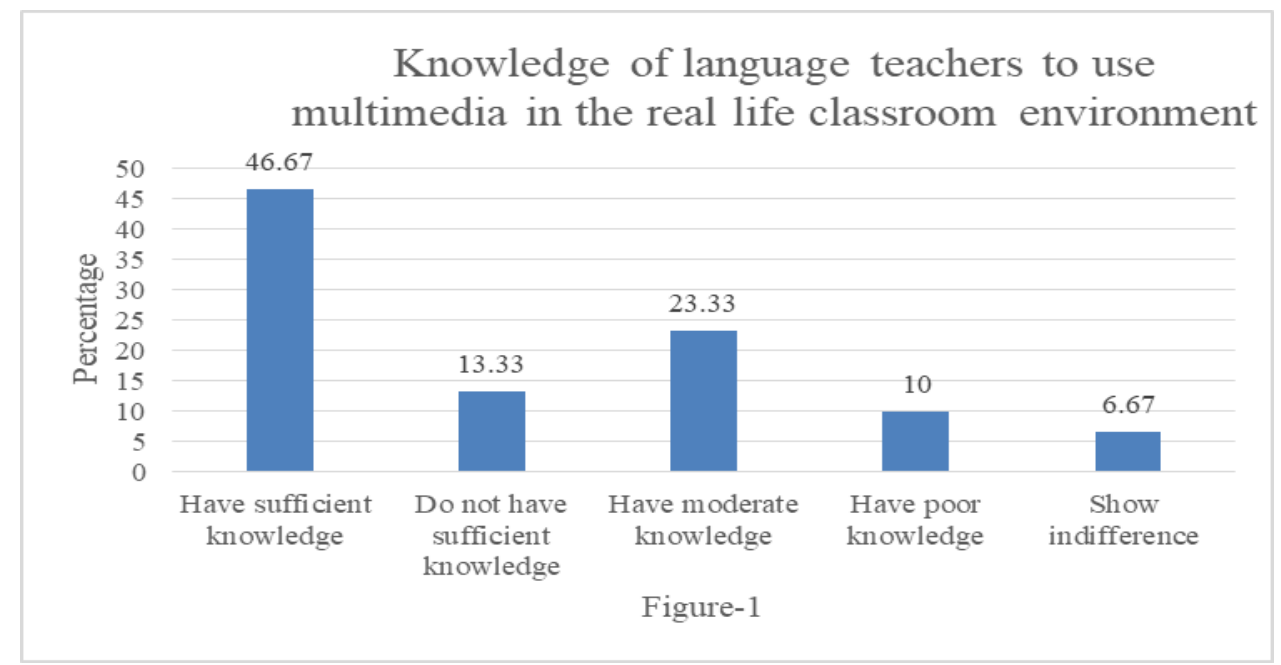

Figure-1 shows that 46.67 percent ELT teachers possess sufficient knowledge in conducting class with the aid of multimedia, 23.33 teachers have moderate capacity to conduct a class with multimedia equipped, 13.33 percent teachers think they do not have enough knowledge in multimedia furnished class, 10 percent teachers express that they have poor familiarization with the multimedia oriented class and 6.67 percent teachers express no sense of interest in using multimedia based class effectively.

\subsection{Do students face obstruction in learning English as Second Language (ESL) through multimedia?}

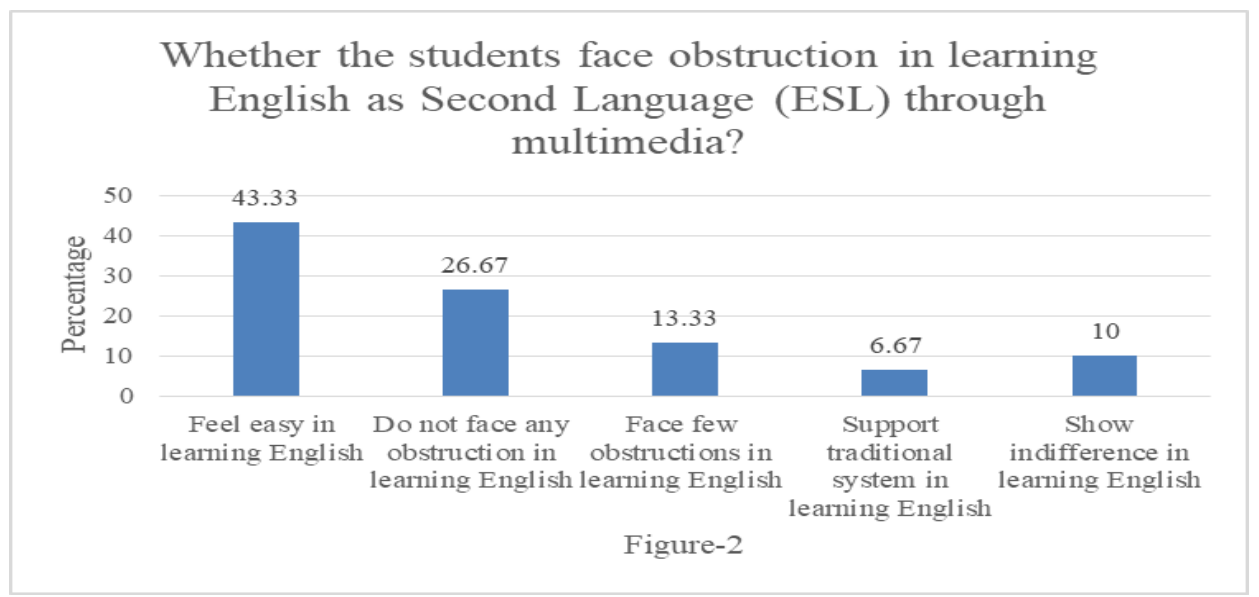


Figure-2 explains 43.33 percent teachers say students have easiness in teaching-learning of English with the aid of multimedia, 13.33 percent teachers say students face few obstructions when they take class with multimedia technology, 26.67 percent teachers say that students do not face any kind of obstruction in learning English when they are in multimedia oriented classroom. On the contrary, 6.67 percent teachers think students support traditional pattern of classroom instead of multimedia classroom and 10 percent teachers say students have no any saying about multimedia oriented classroom.

8.3 Do teachers think multimedia gives a sufficient breakthrough to the traditional language teaching-learning in Bangladesh?

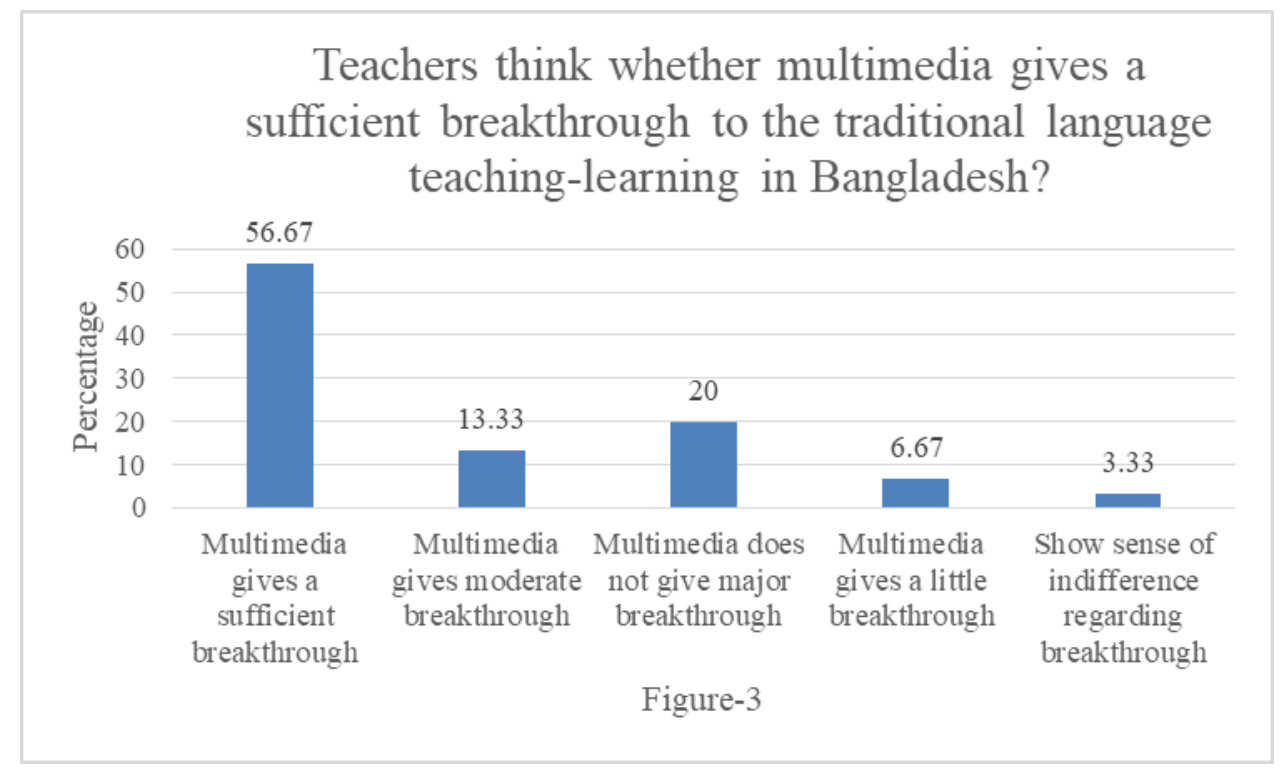

Figure-3 demonstrates 56.67 percent teachers say multimedia gives a strong breakthrough to the traditional language teaching-learning in Bangladesh. On the other hand, 20 percent teachers say multimedia does not have any impact upon traditional language teaching. 13.33 percent teachers opine that multimedia gives a moderate breakthrough against traditional ELT in Bangladesh. Against this scenario, 6.67 percent teachers say multimedia poses a little impact on conventional system of teaching and 3.33 percent teachers show sense of indifference in this regard.

8.4 Are teachers comfortable with the application of multimedia in English language teaching?

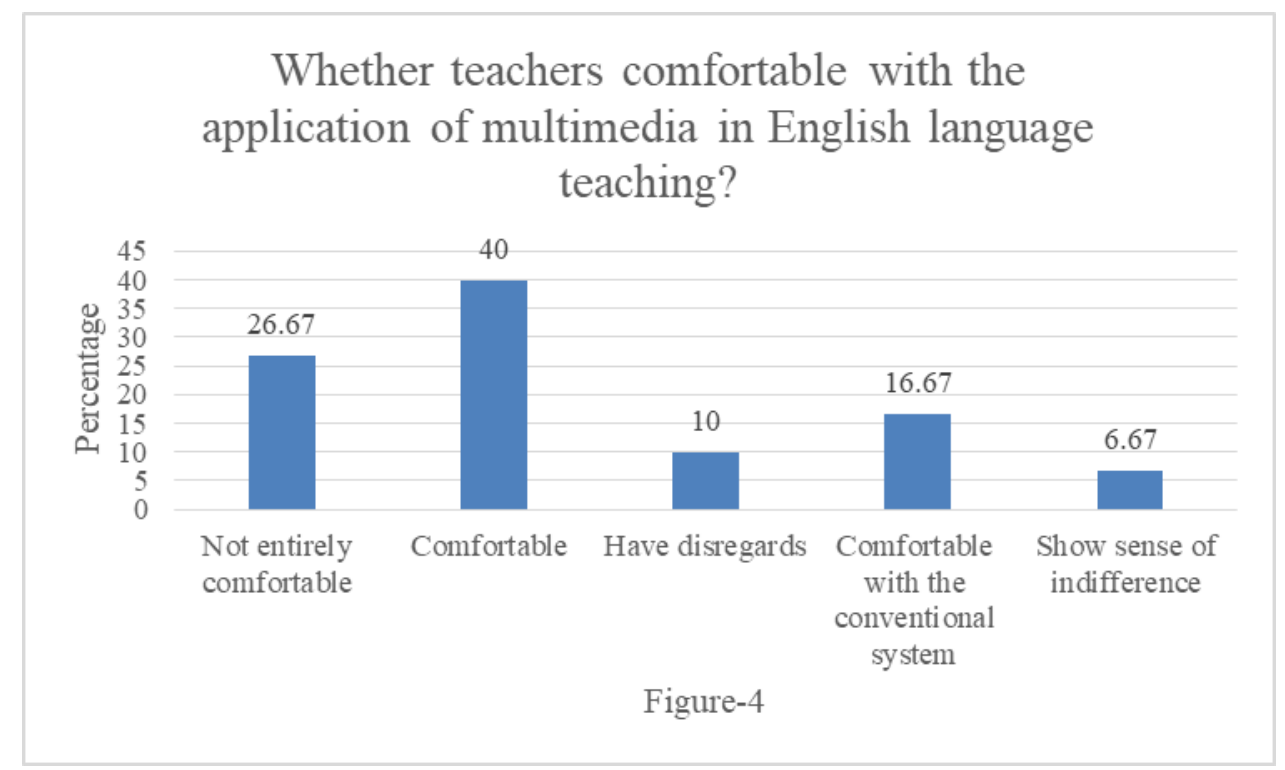


Figure-4 shows 40 percent teachers are comfortable and adjusted with multimedia system in ELT. Conversely, 26.67 percent teachers say that they are not entirely comfortable with multimedia system in ELT, 16.67 percent teachers say they are only adjusted with conventional system in ELT. 10 percent teachers say they do not have any kind of good impression regarding ELT in Bangladesh and 6.67 percent teachers tell they have no interest about multimedia system in the sphere of teaching-learning of Bangladesh.

8.5 Is multimedia as practicable and pragmatic concept in the English language teaching arena of Bangladesh?

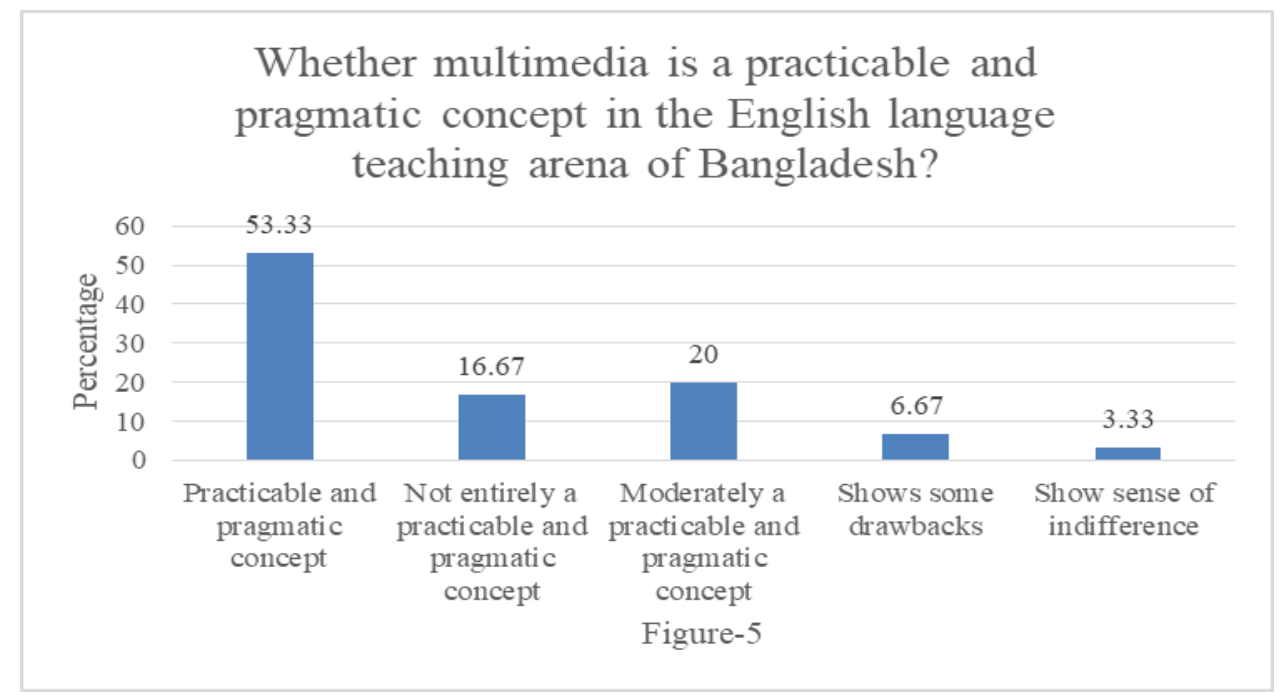

Figure-5 demonstrates that 53.33 percent teachers agree that multimedia is practicable and pragmatic in ELT of Bangladesh, 20 percent teachers say that multimedia is moderately or partially practicable and pragmatic in the context of Bangladesh. On the other hand, 16.67 percent teachers say that the concept of multimedia is not entirely practicable and pragmatic for many reasons and that is why 6.67 percent teachers talk about drawbacks of multimedia, while 3.33 percent teachers remain neutral in making comments in this regard.

9. Limitations of the Study

I faced a number of significant barriers when I conducted this qualitative research on getting what teachers feel about multimedia in ELT classroom and they showed tone of indifference to my work. Subsequently, I was able to manage them to support me to conduct my work for good output. It is relevant to confess that I made my research work upon 30 teachers only of which 7 from school level, 8 from college level and 15 from university or tertiary level education of Bangladesh. I think it would be better, more effective and more acceptable if I found more participants in my research work because it would ensure more authenticity and relevancy. In my research work, there is one determiner that teachers showed a sense of indifference to my question. It would be more effective, if they gave their comments to my questionnaire and made my work qualitative. In addition, the number of questions set in questionnaire was sufficient and more questions needed to be set in this regard.

10. Conclusion

The concept of multimedia in English Language Teaching (ELT) is a mile stoning and significant as teachers and students have positive impression and they look for such kind of teaching-learning which will go in terms of the needs and necessities of language teaching. It can be said that teaching-learning has become easier and more understandable with computer-based presentation technology because it has the combination of textual presentation in line with technological assistances. Since the whole world becomes a global village and English language teaching-learning becomes flourished with modern technology, Bangladesh is subject to move with the pace of present age marked as 'Information and Communication Technology'. From primary to university education, we can find a wide availability and utility of the application of multimedia, its accessories and essential scopes in ELT of Bangladesh. Modernization with technological materials, decoration with electronic devices and furnish with necessary equipment of classroom are the indication that traditional method English language teaching in Bangladesh is going through a number of significant changes. Political anarchy, limitation of financial resources, constraints of assets and adaptation with change and suitability with time are major obstacles in the way of implementation of ideal pedagogy-multimedia aided language teaching in the context of Bangladesh.

References

Amin, B., Benachaiba, C., \& Guemide, B. (2013). Using multimedia to motivate students in EFL classrooms: A case study of English master's students as Jijel University, Algeria. Malaysian Journal of Distance Education, 14(2), 63-81. 
Baker, R., Minh Do, D. and Mailand, S. (2015). The Use of Technology to Enhance English Language (ESL) Teaching. Worcester Polytechnic Institute in cooperation with The Caritas Institute of Higher Education. http://www.wpi.edu/Academics/Project

Boles, S. R. (2011, Summer). Using technology in the classroom. Science Scope, 34(9): 39.

Educational Technologies for English Language Learners, (2010). Center for Digital Education. www.centerdigitaled.com

Evans, M. (2009). Foreign---Language Learning with Digital Technology. London: Continuum.

Ferry, B. and Brown, C. (1995). Technology in Teacher Education: Using Multimedia to Enhance the Design and Make Processes. Vol. 20, No. 2. University of Wollongong

Harmer, J. (2001). The Practice of English Language Teaching. Essex: Longman Group UK Ltd.

McDonough, J., Shaw, C. and Masuhara, H. (2013). Materials and Methods in ELT: A Teacher's Guide. Willey Blackwell.

Nunan, D. (1999). Second Language Teaching and Learning. Boston, MA: Heinle \& Heinle.

Nunan, D. (2003). The Impact of English as a Global Language on Educational Policies and Practices in the Asia---Pacific Region. TESOL Quarterly, 37(2), 589-613.

Parveen, R. (2013). ICT in Education: Issues in using computer and multimedia in the classroom context of Model Primary Schools in Bangladesh. Bangladesh Reading Association (BRA) Journal for Classroom Teaching

Passey, D., Rogers, C., Machell, J., and McHugh, G. (2004). The Motivational Effects of ICT on Pupils. London, UK: DfES.

Prime Minister's Office. (2010). A Brief on Strategic Priorities of Digital Bangladesh. Access to

Information. Dhaka: Government of Bangladesh. www.a2i.pmo.gov.bd

Prime Minister's Office. (2014). ICT in Education. Access to Information. Dhaka: Government of Bangladesh. www.a2i.pmo.gov.bd

ProEnglish. (2014). Official English in the World. Retrieved on December 13, 2014, from https://www.proenglish.org/official---english/official---english---around---the--world.html

S. Lin and X. Huang (Eds.): Study on the Application Multimedia in English Language Teaching. CSEE 2011, Part IV, CCIS 217, pp. 293-297, 2011. (C) Springer-Verlag Berlin Heidelberg 2011

Susikaran, R.S.A. (2015). The Use of Multimedia in English Language Teaching. Journal of Technology for ELT.

Warschauer, M. and Kern, R. (2000). Network-based Language Teaching: Concepts and Practice. Cambridge University Press

\section{Copyrights}

Copyright for this article is retained by the author(s), with first publication rights granted to the journal.

This is an open-access article distributed under the terms and conditions of the Creative Commons Attribution license (http://creativecommons.org/licenses/by/4.0/) 